\title{
EVALUASI MANAJEMEN RESIKO TEKNOLOGI INFORMASI MENGGUNAKAN KERANGKA KERJA COBIT 5.0
}

\author{
${ }^{1}$ Megawati, ${ }^{2}$ Ana Syntia \\ ${ }^{1,2}$ Program Studi Sistem Informasi, Fakultas Sains dan Teknologi, UIN SUSKA Riau, \\ Jl. HR Soebrantas, KM. 18.5, No. 155, Simpang Baru, Pekanbaru, Indonesia, 28293. \\ Email: ${ }^{1}$ megawati@uin-suska.ac.id, ${ }^{2}$ anasinthya10@gmail.com
}

\begin{abstract}
ABSTRAK
PT. Pegadaian adalah lembaga keuangan bukan bank yang kegaiatannya memberikan kredit kepada masyarakat melalui gadai. Dalam hukum gadai, peminjam wajib menyerahkan barang (harta) kepada pegadaian sebagai Jaminan. Pegadaian juga memiliki hak untuk menjual atau melakukan lelang atas barang (harta) jaminan jika telah melalui batas waktu atau jatuh tempo pembayaran atau pelunasan. Pada bagian TI, PT.Pegadaian belum pernah melakukan evaluasi terhadap Sistem Informasi (SI) atau Teknologi Informasi (TI) yang telah diterapkan dari sisi kemajuan mencapai tujuan serta nilai tata kelola dan manajemen teknologi informasi. Sehingga sampai saat ini bagian TI PT. Pegadaian belum dapat mengetahui sejauh mana manfaat dan dampak yang diperoleh dari penerapan SI/TI tersebut terhadap progresivitas pencapaian tujuan dikaitkan dengan pengelolaan sistem informasi, apa yang menjadi kekurangan, serta apa tawaran solusinya. Sehingga diperlukannya evaluasi terhadap manajemen risiko yang terjadi pada PT. Pegadaian. Adapun metode yang digunakan dalam penelitian ini adalah menggunakan COBIT framework versi 5.0. Fokus domain COBIT yang digunakan pada penelitian ini adalah EDM.03 Evaluate, Direct dan Monitor. Hasil akhir dari laporan ini berupa nilai kapabilitas serta rekomendasi untuk pencapaian tingkat kapabilitas terkait proses Evaluate, Direct, dan Monitor.
\end{abstract}

Kata Kunci: evaluasi, manajemen risiko, PT. Pegadaian, COBIT 5.0, EDM.03

\section{A. PENDAHULUAN}

E-Government merupakan sistem pemerintahan dengan berbasis elektronik agar dapat memberikan kenyamanan, meningkatkan transparansi dan meningkatkan interaksi dengan masyarakat, serta meningkatkan partisipasi publik. Pengembangan E-Government di Indonesia sudah dilaksanakan dibeberapa daerah sebagai turunan pemerintah yang selalu berupaya untuk melayani publik.

PT. Pegadaian adalah lembaga keuangan bukan bank yang kegaiatannya memberikankredit kepada masyarakat melalui gadai. PT.Pegadaian memiliki Sistem Informasi UnderWeb yang diharapkan dapat menjadi role model bagi seluruh BUMN maupun Seluruh kantor pada PT.Pegedaian dalam penyaluran dana publik. Namun, pada bagian TI, PT.Pegadaian belum pernah melakukan evaluasi terhadap Sistem Informasi/Teknologi Informasi (SI/TI) yang telah diterapkan dari sisi kemajuan mencapai tujuan serta nilai tata kelola dan manajemen teknologi informasi [1]. Sehingga sampai saat ini bagian TI PT.Pegadaian belum dapat mengetahui sejauh mana manfaat dan dampak yang diperoleh dari penerapan SI/TI tersebut terhadap progresivitas pencapaian tujuan dikaitkan dengan pengelolaan sistem informasi, apa yang menjadi kekurangan, serta apa tawaran solusinya [2].

Adapun metode yang digunakan dalam penelitian ini adalah menggunakan COBIT framework versi 5.0. menurut ISACA [3], COBIT 5 merupakan generasi terbaru dari panduan ISACA yang membahas mengenai tata kelola dan manajemen IT. Dalam COBIT 5 saat ini terbagi menjadi 5 Domain yang terdiri dari 37 proses. Adapun 5 Domain tersebut adalah Evaluate, Direct and Monitor (EDM) 5 proses; Align, Plan and Organise (APO) 13 proses; Build, Acquire and Operate (BAI) 10 proses; Deliver, Service and Support (DSS) 6 proses; dan Monitor,Evaluate and Assess (MEA) 3 proses.

Fokus domain COBIT yang digunakan pada penelitian ini adalah EDM.03 Evaluate,Direct dan Monitor. Pemilihan domain COBIT EDM.03 ini didasari dengan permasalahan yang terjadi yaitu bagaimana tingkat telah terlaksananya visi dan misi, tujuan layanan, kebijakan dan prosedur yang telah diterapkan dan pengendalian yang dilakukan terhadap internal oleh PT. Pegadaian Kota Pekanbaru. Dengan menggunakan domain COBIT EDM.03 ini sudah dapat menjelaskan dan mendefinisikan kerangka kerja control serta mengkomunikasikan kebijakan tersebut. Komunikasi berkelanjutan melalui program ini yang dilaksanakan untuk mengartikulasikan visi dan misi,tujuan layanan, kebijakan dan prosedur, disetujui dan didukung oleh manajemen.

Metode yang digunakan dalam menganalisa menggunakan COBIT Framework 5.0. Penelitian dibatasi pada proses TI yaitu EDM.03 (Evaluate,Direct dan Monitor). Penelitian ini 
meliputi penilaian tingkat kapabilitas penerapan sistem UnderWeb menggunakan Process Assessment Model (PAM).

\section{B. STUDI PUSTAKA}

\section{B.1. Manajemen Risiko}

Manajemen risiko adalah proses identifikasi pengkajian, serta pengembangan strategi mitigasi dan komunikasi risiko TI yang memiliki potensi merugikan atau berdampak negative terhadap organisasi [4]. Kontrol dan pengukuran kinerja manajemen risiko dilakukan oleh semua pihak dengan menentukan risiko mana yang harus mendapat perhatian dan pada level mana risiko dapat diterima oleh organisasi. Sebagaimana risiko TI merupakan risiko pada organisasi yang disebabkan oleh penggunan TI dalam suatu organisasi, terdiri dari semua kejadian yang terkait dengan penggunaan TI dan memiliki potensi yang berdampak pada organisasi [5].

\section{B.2. COBIT 5}

Control Objective for Information and Related Technology (COBIT) merupakan seperangkat pedoman dan hasil dokumentasi yang berfungsi untuk membantu auditor, pemangku kepentingan atau pengguna (user) dalam menghubungkan antara model kendali bisnis dan model kendali TI. COBIT dikembangkan untuk menerapkan Governance of Enterprise IT. Versi terbaru yang dikeluarkan oleh IT Governance Institute dikenal sebagai COBIT 5. COBIT 5 terbentuk dengan mengintegrasikan Risk IT framework, VAL IT 2.0 dan COBIT 4.1. Selain itu COBIT 5 juga menyesuaikan antara best practices yang ada seperti ITIL V3, TOGAF dan standart relevan dari ISO [2].

COBIT 5 sebuah kerangka kerja generasi terbaru dari panduan ISACA yang memebahas mengenai tata kelola dan manajemen TI. COBIT 5 menyediakan kerangka kerja yang membantu perusahaan dalam mencapai tujuan mereka dengan tata kelola dan manajemen teknologi informasi [6]. COBIT 5 memungkinkan TI untuk mengatur dan mengelola secara menyeluruh dalam perusahaan, dengan mempertimbangkan penuh bisnis dan bidang fungsional TI dari tanggung jawab dan mempertimbangkan kepentingan terkait TI [7].

Prinsip pada COBIT 5 antara lain [7]:

(1) Memenuhi Kebutuhan Stakeholder (Meeting Stakeholder Needs)

(2) Melingkupi Seluruh Perusahaan (Covering the End-to-End)

(3) Menerapkan Suatu Kerangka Tunggal yang Terintegrasi (Applying a Single Integrated Framework)

(4) Menggunakan sebuah pendekatan yang menyeluruh (Enabling a Holistic Approach)

(5) Pemisahan Tata kelola Dari Manajemen (Separating Governance from Management)
Prinsip pada COBIT 5 dapat dilihat pada Gambar 1.

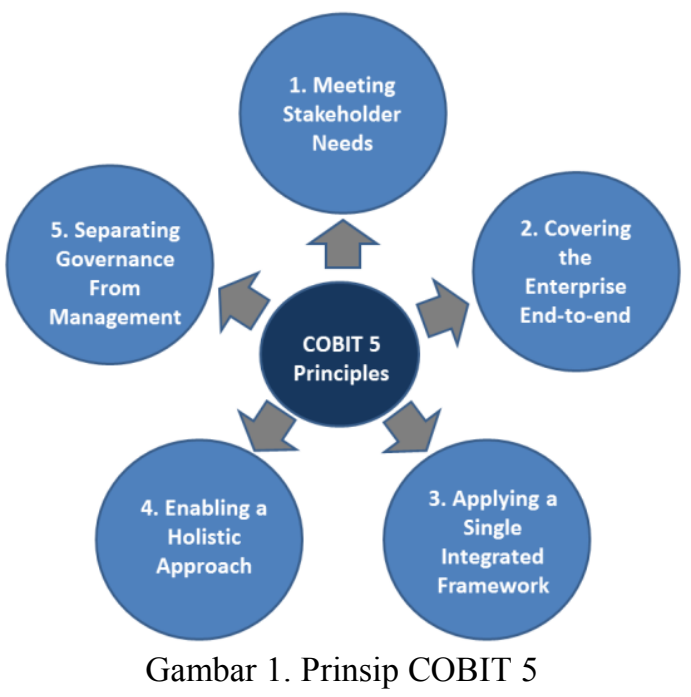

Dalam melakukan evaluasi, ISACA [8] menjelaskan bahwa terdapat tujuh buah tahapan yang harus diterapkan menurut siklus implementasi COBIT 5, antara lain [8]:

(1) Initiate Progamme, pada tahap ini dilakukan identifikasi faktor yang menjadi pendorong perubahan dan apa saja yang harus diubah. Tujuan tahap ini adalah untuk memperoleh pemahaman, pendalaman tentang tujuan, tugas, dan wewenang suatu organisasi.

(2) Define Problems and Opportunities, tahap ini mendefinisikan keberadaan posisi suatu organisasi saat ini, dan memperioritaskan tujuan dan juga proses TI, dan menyelaraskan tujuan TI dengan strategi dan risiko perusahaan.

(3) Define Road Map, tahap ini menetapkan target untuk perbaikan yang diikuti dengan analisis gap untuk mengidentifikasi solusi yang potensial.

(4) Plan Progamme, tahap ini merupakan tahapan rencana untuk solusi yang mudah dan praktis dengannmendefinisikan proyek yang didukungnoleh proses bisnis dan mengembangkannrencananiperubahan untuk diimplementasikan serta memastikan bahwa manfaat proyek diidentifikasi dan terus dimonitor.

(5) Execute Plan, pada tahap ini menyediakan pelaksanaan dari solusi yang telah diusulkan ke dalam praktik kerja sehari-hari dan melakukan pemantauan hasil kerja.

(6) Release Benefits, tahap ini berfokus pada kelanjutan dari hasil perbaikan tata kelola teknologi informasi dan manajemen praktik dalam operasional bisnis.

(7) Review Effectivenes, tahap ini merupakan ulasan keberhasilan dari pencapaian seluruh 
dan meningkatkan kebutuhan untuk perbaikan secara terus-menerus.

\section{METODOLOGI}

Adapun tahapan pada penelitian ini dapat dilihat pada Gambar 2.

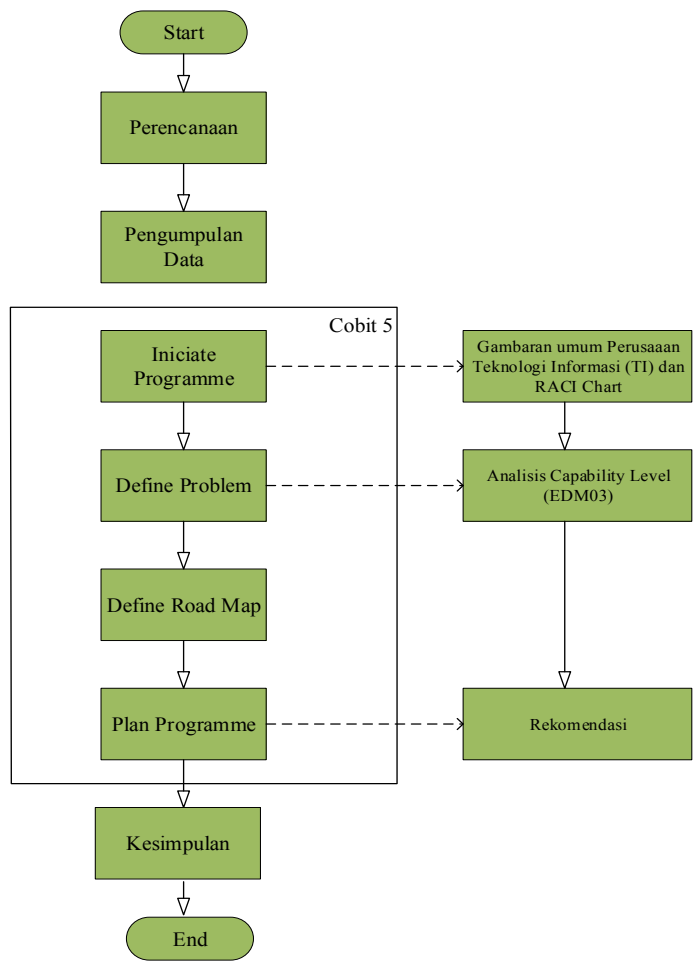

Gambar 2. Metodologi penelitian berikut:

Metode penelitian meliputi 6 langkah sebagai

(1) Menentukan objek dan subjek penelitian, menentukan kerangka kerja yang tepat serta menggali informasi yang terkait pada PT.Pegadaian (Persero).

(2) Melakukan pengumpulan data, baik data primer maupun data sekunder dengan cara melakukan penyebaran kuesioner, melakukan observasi langsung, melakukan wawancara dengan pihak pihak yang berwenang dan studi kepustakaan.

(3) Mendeskripsikan gambaran umum mengenai kondisi umum organisasi, visi dan misi sebagai tujuan organisasi, gambaran umum sistem informasi atau teknologi informasi yang diterapkan dan pihak-pihak yang bertanggung jawab dalam penerapan manajemen risiko berdasarkan RACI Chart.

(4) Melakukan analisis penilaian Capability Level berdasarkan kerangka kerja COBIT 5 khususnya domain proses EDM03 (Ensure Risk Optimisation).

(5) Membuat rekomendasi untuk menentukan solusi potensial berdasarkan hasil analisis Capability Level.

(6) Menyusun kesimpulan yang berisi ringkasan tentang semua langkah - langkah yang telah dilalui dalam melakukan penelitian.

\section{PEMBAHASAN}

Berdasarkan hasil pembuatan RACI Chart, dapat diketahui bahwa pihak yang berhak menjadi responden untuk mengisi kuesioner adalah sejumlah empat orang, antara lain Staf Bisnis Analis, Asmen Risiko Bisnis Analis, Profesional IT Madya Keuangandan Pengelolaan Aset [9]. Berikut ini ringkasan pengelolaan data dan pencapaian level proses EDM 03 yang telah dijelaskan pada Tabel 1.

Tabel 1. Ringkasan pengelolaan data pada proses EDM 03

\begin{tabular}{|c|c|c|c|c|}
\hline Nama Proses & \multicolumn{4}{|c|}{ EDM.03 } \\
\hline Tujuan & \multicolumn{4}{|c|}{$\begin{array}{l}\text { Mendapatkan hasil dari pencapaian tujuan } \\
\text { dalam perusahaan serta pemahaman } \\
\text { tentang resiko dalam perusahaan dan } \\
\text { mendapat kesesuaian sistem pengendalian } \\
\text { internal dimana sistem pengendalian } \\
\text { internal merupakan proses manajemen } \\
\text { untuk tercapainya tujuan perusahaan }\end{array}$} \\
\hline Level & 1 & 2 & & 3 \\
\hline Proses Atribut & & $\begin{array}{l}\text { PA } \\
2.1\end{array}$ & $\begin{array}{l}\text { PA } \\
2.2\end{array}$ & $\begin{array}{l}\text { PA } \\
3.1\end{array}$ \\
\hline $\begin{array}{l}\text { Rating by } \\
\text { Percentage }\end{array}$ & 87.50 & 76.04 & 85.94 & 78.75 \\
\hline $\begin{array}{l}\text { Rating by } \\
\text { Criteria }\end{array}$ & $\mathrm{F}$ & $\mathrm{L}$ & $\mathrm{L}$ & $\mathrm{L}$ \\
\hline $\begin{array}{l}\text { Capability } \\
\text { Level } \\
\text { Percentage } \\
\text { Achieved }\end{array}$ & 87.50 & 80.99 & & 80.00 \\
\hline Status & & Tidak & rcapai & $\begin{array}{l}\text { Level } \\
\text { Target }\end{array}$ \\
\hline
\end{tabular}

Dari Tabel 1 diatas, dapat diketahui bahwa hasil pengisian kuesioner yang dilakukan oleh empat orang responden menunjukkan nilai Capability Level terkait proses EDM03 berada pada Level 1.

\section{D.1. Analisis kondisi saat ini}

Dalam mengelola proses bisnis perusahaan, PT.Pegadaian (Persero) telah melakukan penerapan sistem yang bernama UnderWeb. Sistem tersebut diharapkan mampu mengintegrasikan seluruh proses bisnis yang ada pada perusahaan dan mensinergiskan proses bisnis dari masing masing anggota pegadai.

Dalam hal ini, pihak yang bertanggung jawab mendukung jalannya Sistem UnderWeb, yang mengintegrasikan sistem atau aplikasi yang dibuat sendiri oleh PT.Pegadaian (Persero), serta meningkatkan kualitas SDM untuk mendukung penerapan Sistem UnderWeb adalah Departemen BUMN. Dalam penerapan Sistem UnderWeb tersebut, tidak pernah lepas dari suatu risiko. Oleh karena itu untuk mengelola segala bentuk risiko perusahaan, Departemen BUMN \& PT.Pegadaian telah menerapkan manajemen risiko berdasarkan 
standart dan kebijakan yang ditetapkan yaitu ISO 31000 : 2009. Standart dan kebijakan tersebut tertuang dalam dokumen Kebijakan Manajemen Risiko, Pedoman Penerapan Manajemen Risiko, Prosedeur Penerapan Manajeen Risiko, Panduan Penilaian Penerapan Manajemen Risiko dan Pedoman Manajemen Risiko PT. Pegadaian (Persero). Selama ini penerapan manajemen risiko pada PT. Pegadaian dimulai dengan melakukan identifikasi terhadap semua risiko yang muncul, menganalisis setiap risiko yang telah diidentifikasi, mengevaluasi setiap risiko, pengendalian dan penanganan risiko serta monitoring dan review terhadap pengendalian dan penanganan. Selanjutnya hasil dari aktivitas pengelolaan risiko tersebut disusun dalam sebuah dokumen yang bernama Profil Risiko PT. Pegadaian (Persero).

\section{D.2. Hasil Temuan}

Berdasarkan hasil analisis capability level yang diperoleh dari perhitungan hasil kuesioner dan proses wawancara dengan pihak PT. Pegadaian (Persero), didapatkan beberapa temuan berikut :

(1) Adanya layanan Tata Kelola Perusahaan dan Manajemen Risiko pada PT. Pegadaian, namun belum adanya manajemen atau team yang dibentuk secara khusus untuk mengelola segala macam risiko terkait dengan teknologi informasi.

(2) Pengelolaan risiko yang dilakukan oleh PT. Pegadaian masih secara umum yaitu dilakukan pada seluruh unit kerja perusahaan dan belum berfokus secara spesifik pada penerapan teknologi informasi.

(3) Tidak semua risiko teknologi informasi telah didokumentasikan dan dikelola dengan baik.

(4) Dalam melakukan analisis risiko tersebut, belum disertai dengan analisis cost benefit yaitu perkiraan frekuensi besarnya keuntungan dan kerugian yang berhubungan dengan penanganan setiap skenario risiko.

\section{D.3. Analisis Capability Level}

Berdasarkan hasil pengisian lembar kerja evaluasi yang dilakukan oleh 4 responden dari Bagian Analis,Bagian Keuangan dan Bagian IT Pada PT.Pegadaian dapat diketahui bahwa nilai capability level yang telah dicapai subdomain EDM03 berada pada level 1 .

\section{D.4. Rekomendasi}

Rekomendasi dibuat mengacu kepada hasil analisis capability level guna mengetahui pencapaian menjalankan proses saat ini. Rekomendasi dibuat dengan tujuan dan target yang telah ditentukan, maupun untuk mencapai target yang telah ditentukan oleh PT.Pegadaian dalam melakukan analisa manajemen risiko teknologi informasi. berikut merupakan rekomendasi dari Domain proses EDM03 sebagai berikut:
(1) PT Pegadaian Kanwil Pekanbaru disarankan untuk membentuk team khusus yang mempunyai tanggung jawab dalam melakukan pembahasan dan pengelolaan terkait penerapan manajemen riiko teknologi informasi di dalam perusahaan.

(2) Membuat dokumen kontrol pertama staff, yang terdiri dari hasil kinerja dari penerapan manajemen risiko

(3) Menerbitkan dokumen kontrol berupa check list pada saat implementasi penerapan manajemen risiko.

(4) Memperkuat kegiatan monitoring penerapan manajemen risiko teknologi informasi untuk bahan evaluasi, agar penerapan manajemen risiko dapat terus diperbaharui dan kekurangan yang belum teridentifikasi.

(5) Menerbitkan suatu kebijakan dalam melakukan pengukuran terhadap pengelolaan standart proses.

(6) Meningkatkan perumusan proses standart yang akan diterapkan, mendefinisikan detail

(7) tanggung jawab dan otoritas pelaksanaan aktifitas.

(8) Melakukan pengukuran terhadap sejauh mana proses standart dikelola untuk mendukung pengerjaan dari proses yang telah didefeniikan.

(9) Membuat program-program khusus yang berisi kegiatan pemantauan, review, pengendalian, dan pengelolaan terhadap penerapan manajemen risiko teknologi informasi.

(10) Mengumpulkan data-data relevan yang dapat dijadikan sumber untuk memastikan kecocokan dan keefektifan proses sebagai bahan evaluasi untuk perbaikan terus-menerus dari proses.

(11) PT Pegadaian Kanwil Pekanbaru harus memastikan kebijakan tentang manajemen risiko yang berkaitan dengan teknologi informasi juga harus terintegrasi atau selaras dengan manajemen risiko secara keseluruhan perusahaan.

\section{E. KESIMPULAN}

Berikut ini, merupakan hasil kesimpulan dari hasil penelitian analisis proses EDM03 evaluasi, direct and monitor terkait penerapan sistem UnderWeb berdasarkan kerangka kerja COBIT 5 pada PT.Pegadaian (Persero) Pekanbaru, maka dapat diperoleh kesimpulan bahwa dalam penerapan tingkat kapabilitas proses evaluasi, direct and monitor terkait penerapan sistem under web pada PT Pegadaian Kota Pekanbaru dengan hasil pencapaian yang diperoleh berada pada level 1 (Performed Process) dan persentase yang diraih yaitu $87.50 \%$. Dan terdapat 10 rekomendasi. 


\section{REFERENSI}

[1] Fitri, Ai Dila. 2015. Evaluasi Sistem Informasi Manajemen Kepegawaian (SIMPEG) Pada Pengadilan Tinggi Agama Pekanbaru Berdasarkan Kerangka Kerja COBIT 5. [Skripsi] Program Studi Informasi, Universitas Islam Negeri Sultan Syarif Kasim Riau.

[2] Branikno, Ramadhan. 2018. Analisa Proses Monitoring, Evaluasi dan Penilaian Pengendalian Internal Sistem Informasi E-KTP Menggunakan COBIT 5.0 (Studi Kasus: Dinas Kependudukan dan Pencatatan Sipil Kota Dumai). [Skripsi] Program Studi Sistem Informasi, Universitas Islam Negeri Sultan Syarif Kasim Riau.

[3] ISACA. 2013. COBIT 5 for Risk.

[4] Firdaus, Nurfitri Zukhrufatul., Suprapto. 2018. Evaluasi Manajemen Risiko Teknologi Informasi Menggunakan COBIT 5 IT Risk (Studi Kasus: PT.
Petrokimia Gresik). Jurnal Pengembangan Teknologi Informasi dan Ilmu Komputer. 2(1): 91100.

[5] ISACA. 2014. COBIT 5: A Business Framework for the Governance and Management of Enterprise $I T, 2013$. ISACA ISBN 1963669381.

[6] ISACA. 2012. COBIT 5: The Risk IT Practitioner Guide

[7] Arief, M. Habibullah., Suprapto., 2018. Evaluasi Manajemen Risiko Teknologi Informasi Menggunakan Kerangka Kerja COBIT 5 (Studi Kasus Pada Perum Jasa Tirta I Malang). Jurnal Pengembangan Teknologi Informasi dan Ilmu Komputer. 2(1): 101-109.

[8] ISACA. 2012. COBIT 5: Enabling processes.

[9] ISACA. 2013. COBIT Self Assessment Guide: Using COBIT 5. USA: ISACA. 